\title{
EQUiLIBRIUM
}

Quarterly Journal of Economics and Economic Policy

2014 VOLUME 9 ISSUE 3, September

p-ISSN 1689-765X, e-ISSN 2353-3293

www.economic-policy.pl

Rószkiewicz M.M. (2014), On the Influence of Science Funding Policies on Business Sector R\&D Activity, "Equilibrium. Quarterly Journal of Economics and Economic Policy", Volume 9, Issue 3, pp. 9-26, DOI: http://dx.doi.org/10.12775/EQUIL.2014.015

\author{
Marta Magdalena Rószkiewicz*
}

National Information Processing Institute, Poland

\section{On the Influence of Science Funding Policies on Business Sector R\&D Activity}

JEL classification: 031,038

Keywords: science policy effectiveness; direct and indirect funding

\begin{abstract}
The analysis focuses on assessing the impact of science and innovation policy on increasing business research activity, represented by the measure of business expenditure on research (BERD). The study concentrates on the impact of direct and indirect funding instruments. The effects of public intervention were examined basing on the pursued policy and the country's level of innovativeness in 21 countries. In order to build aggregate variables of direct and indirect financial flows, the procedure of principal components was performed. Correlations between these variables and business sector activity were examined. The procedure of hierarchical clustering allowed to determine groups of countries which used similar policy instruments and experienced the same dynamics of BERD expenditures. The aim of such clustering was to highlight basic types of relations between the policy pursued and the activity of business sector. The study allowed to determine that direct funding has a significant effect on increasing BERD expenditures and is decreasing with the growing intensity of these outlays. The relation for indirect funding was found to be more complex. The generosity of country's tax incentives for $R \& D$ was proved to be dependent on the level of innovativeness of business sector and was represented by an inverted $U$-shaped curve. The level of innovativeness was also found to have a stronger impact on business sector research
\end{abstract}

(C) Copyright Institute of Economic Research \& Polish Economic Society Branch in Torun

Date of submission: May 12, 2013; date of acceptance: March 15, 2014

* Contact: marta.roszkiewicz@opi.org.pl, Ośrodek Przetwarzania Informacji, Al. Niepodległości 188b, 00-608, Warszawa, Poland 
activity than the policy pursued by a country. Basic recommendations on research funding policies were built based on the performed analysis.

\section{Introduction}

Both economic theory and empirical analysis emphasize the importance of knowledge in the process of economic growth (Griliches, 1979; Romer, 1990). Innovativeness is a key factor of productivity growth and in the process of strengthening country's competitiveness. This idea is a central concept in the model of Knowledge-Based Economy (KBE), adopted by many European and world economies. The KBE model describes a system based on intensive application of innovation in production processes, in which the competitiveness of a country is determined by its human resources, knowledge and technology. The model emphasizes the engagement of business sector in funding and performing research, as well as adoption of innovation in the professional activity of companies.

A target of private sector's expenditures on research and development (BERD) intensity in GDP has been set at the level of $2 \%$ by many world economies, including European Union (European Commission, 2010). In practice, a varied level and dynamics of BERD expenditures is observed across the European countries and in the world. According to Eurostat, a stable growth of BERD expenditures in relation to GDP was observed in Denmark, United States and Japan in recent years (2002-2011). In other countries, like Sweden, Luxembourg, Romania, and Russia, this intensity decreased. An irregular dynamics of BERD intensity was observed for France, the Czech Republic, Slovakia, Croatia and Israel. These diversified observations raise a question on the effectiveness of science and innovation policy in the countries pursuing the KBE model, which is aimed, among others, at raising private funding of science. The question on the effects of public intervention appears to be of high importance, as one can observe an increase of public investment in research and development in the last decade. According to Eurostat, only in the EU countries public expenditures on research has grown from 133 EUR to 170 EUR per capita between 2002 and 2010 , what is a $0,5 \%$ growth in relation to GDP of the EU.

Economic theory states several reasons for public intervention on R\&D market. The regulating institutions are engaged in funding research activities in order to satisfy the needs of the society on knowledge development when these needs cannot be met by private investors (mainly in such sectors as: defense, public health, education) (Sapolsky \& Taylor, 2011). Moreover, the allocation of funds on research is not optimal due to peculi- 
arity of the R\&D market. According to Arrow (1962), imperfect appropriability and diffusion of knowledge beyond control of the inventor implies that private rate of return to $R \& D$ is lower that the social rate of return. The difference between these rates should be compensated by a regulating institution in a process called spillover effect, in which the knowledge is disseminated to a socially optimal level. Arrow also claims that high risk of research discourages firms from engaging in funding of $R \& D$, therefore public policy should apply instruments of encouragement.

One of the objectives of science and innovation policy is to increase the engagement of business sector in the R\&D market. Public intervention can, however, lead to an ineffective situation when the impact of the policy is not optimal. Ineffective public intervention can crowd out private investment in research, when additional funding shifts the demand curve to the right and therefore raises the cost of knowledge (Reinhalter \& Wolf, 2004). A higher cost of research makes knowledge less attractive to private investors, who spend their money on other, cheaper goods instead. Moreover, an inappropriate allocation of public money can substitute private funding instead of stimulating its investment (by funding research that would be performed anyway). It is also often claimed that any intervention leads to a less effective situation than one caused by market forces (por. Guellec \& van Pottelsbergue, 2003). In this context an increase of public spending on $R \& D$ can cause an opposite to the expected effect.

The aim of this study is to analyze the influence of science and innovation policy on business sector R\&D activity. In consequence, an occurrence of such influence will determine the effectiveness of the analyzed policy in the observed countries. The study was conducted basing on science and innovation policy data for 21 countries in the time period of 2003-2008. The first part of the article introduces the characteristics of funding instruments of science and innovation policy. Next, data and methods of construction are presented. The analysis of the quantitative results within the constructed models is introduced in the third part of the article. The conclusions present the implications of the study at the level of science and innovation policy. 


\section{The analyzed instruments of public intervention}

The intervention on $R \& D$ market is supported by a wide range of policy instruments ${ }^{1}$. For the purpose of the study, the analysis has been focused on financial instruments which can act as a stimulus for R\&D activity of business sector. These instruments can be classified into direct and indirect funding.

Direct funding instruments may directly address business sector (by means of government funding on research performed by business sector) or publicly funded knowledge can be transferred to companies as a result of a spillover effect (by means of government funding on research performed by research entities). This regards the situation when publicly performed research (both basic and applied) is transferred to business sector to provide the basis for later application. Indirect R\&D funding is executed in the form of tax incentives ${ }^{2}$ and can take three forms: tax credits (flat or incremental credits), tax deductions (standard or super deductions or accelerated depreciation), and tax holidays and reductions.

Each of these instruments has a different effect on the growth of innovativeness and is aimed at solving different problems regarding $R \& D$ sector. Direct funding enables regulation of the way research is conducted and is often used to stimulate cooperative research. This activity is aimed at strengthening the network between research institutions and firms in order to stimulate knowledge and technology transfer. Direct funding also reduces the high risk taken by private business while investing in research, and encourages innovative investment. Moreover direct funding generates a value added. However, direct funding comes in the form of recognition and is often criticized for picking the winners. Tax incentives lack this feature, they are available to any business that carries out innovative activity. They are also considered to be more durable than direct funding, which is usually periodic and does not guarantee a continuation of research after the grant contract expires. Tax incentives can also attract foreign capital by creating a favorable environment for innovative business. This instrument is used to support the competitiveness of single companies while direct funding creates more opportunity to cause a spillover effect.

\footnotetext{
${ }^{1}$ Six main science and innovation policy instrument's types can distinguished: legal instruments (legislation), financial instruments, institutional instruments, infrastructural instruments, structural instruments and trade instruments (Technopolis, 2004).

${ }^{2}$ Studies show that tax incentives stimulate the growth of private research expenditures (Gullec \& van Pottelsberghe, 2003; Falk, 2004; Bloom \& Griffin, 2001).
} 


\section{Empirical data used in the analysis}

The analysis was conducted based on quantitative data available in public statistics. The measure of business sector R\&D activity was represented by business expenditures on research (BERD). Science policy reflected in direct funding was represented by three measures. Funding intended for firms that conduct R\&D was expressed by the measure of public expenditure on R\&D performed by business sector (GOVB). The stream of public funding intended for both basic and applied research conducted by research institutes and higher education sector was expressed in the measures of public expenditure on $R \& D$ performed by the public sector and the public expenditure on R\&D performed by the higher education sector (GOVGH). The research activity of higher education institutions was introduced by higher education intramural expenditure on R\&D (HERD).

Indirect funding strategies, reflected in the level of tax incentives for innovative firms were represented by measures of tax subsidy ratio (1-Bindex $\left.^{3}\right)$. The B-index represents the before tax rate of return on one monetary unit of investment on $\mathrm{R} \& \mathrm{D}$, whereas the tax subsidy ratio is the proportion of one monetary unit of $R \& D$ expenditure that is subsidized by tax incentives. In other words, the higher the tax subsidy ratio, the more generous the tax incentive ${ }^{4}$. Due to varied tax regulations, tax subsidy ratios were calculated for both small and medium enterprises (SMEs) and large firms.

Varied R\&D policies will be pursued by innovative countries with a high research activity of the business sector and by countries that are still developing their scientific base and introducing the KBE model. Certain policy-mix ${ }^{5}$ can be therefore more effective in some countries than others. For this reason the variables that help to acknowledge this difference in the policy-mix of various countries were introduced in the study. In order to express the level of a country's business sector innovativeness the measure of BERD intensity in GDP was introduced. In order to broaden the analy-

\footnotetext{
${ }^{3}$ The B-index is a measure of fiscal generosity towards R\&D. It is computed as the present value of before-tax income necessary to cover the initial cost of $R \& D$ investment and to pay the corporate income tax, so that it becomes profitable to perform research activities. It is a kind of average effective rate of taxation of $R \& D$ (Warda, 2001). It does not include tax holidays nor tax reductions.

${ }^{4}$ Negative values of tax subsidy ratio reflect cases where there are no tax incentives and capital assets employed in R\&D cannot be written off in the year they were incurred, but rather are depreciated over time (Warda, 2001).

${ }^{5}$ According to European Commission policy-mix is defined as the set of policy actions taken by governments in the field of $R \& D$ which relate to challenges in the national innovation system (NIS) (CORDIS, http://ec.europa.eu/research/policymix/page.cfm?pageid=164).
} 
sis, the intensity of all direct funding measures in GDP was included in the study.

The data used on direct funding came from Eurostat databases and covered information on 21 countries $^{6}$ in the time period of 2003-2008. Based on this data, measures of dynamics of financial flows were constructed (as difference in logarithms of the expenditures). The measures of tax subsidy ratios were calculated by OECD for the year 2008 .

\section{Modeling the effects of science and innovation policy}

The influence of single instruments of science and innovation policy (analyzed for different time delays) on business sector activity is not reflected in the measures of causality (see Table 1). Both Pearson's linear and Spearman's monotonous correlation measures show lack of or a very weak relation between the pursued policy funding measures and the $R \& D$ funding activity of business sector. This result can be observed for both the delayed values of the analyzed processes as well as their five-year average change. As a consequence, an application of econometric modeling for measuring a linear (or linearized) influence of pursued policy on the activity of business sector is not possible. In order to analyze the direction and strength of the mentioned relations a structured data analysis has been applied.

The aim of applying structured data analysis is to classify the analyzed countries by the pursued policy and the level of effectiveness of their business sector. This will allow to determine main relation types between the influence of intervention on the level and dynamics of business sector R\&D activity.

Diversified levels of analyzed measures for the monitored countries hamper the analysis of the effectiveness of single instruments. Therefore, assuming that the configuration of the levels of analyzed indicators defines the research funding policy of the observed countries and in order to visualize both the information set and the relations between the observations, aggregate measures of policy-mix were built with the principal components analysis. This operation allowed to visualize the observations of pursued policies measures in a two dimensional space. The extracted dimensions (components) reconstructed $74 \%$ of common variability of the inputted

\footnotetext{
${ }^{6}$ The selection of the countries for the purpose of this analysis was based on data availability in order to obtain complete time series for the time period of 2003-2008.
} 
information set. The matrix of coefficients after varimax rotation, describing the binding of the analyzed measures with the constructed components is presented in Appendix 1.

Table 1. Person's (P) and Spearman's (rho-S) correlation coefficients between the dynamics of BERD expenditures and the instruments of pursued science and innovation policies

\begin{tabular}{|c|c|c|c|c|c|c|c|c|c|c|}
\hline \multirow[t]{2}{*}{$\begin{array}{c}\text { Delay } \\
(\mathrm{T}=2 \\
009 / 2 \\
008)\end{array}$} & \multicolumn{2}{|c|}{\begin{tabular}{|c|} 
Dynamics of \\
higher \\
education \\
intramural \\
expenditure on \\
R\&D (HERD) \\
\end{tabular}} & \multicolumn{2}{|c|}{$\begin{array}{l}\text { Dynamics of } \\
\text { public } \\
\text { expenditure on } \\
\text { R\&D in busi- } \\
\text { ness sector } \\
\text { (GOVB) }\end{array}$} & \multicolumn{2}{|c|}{$\begin{array}{l}\text { Dynamics of } \\
\text { public expendi- } \\
\text { ture on R\&D in } \\
\text { public and higher } \\
\text { education sectors } \\
\text { (GOVGH) }\end{array}$} & \multicolumn{2}{|c|}{$\begin{array}{c}\text { Tax subsidy ratio } \\
\text { for SMEs }\end{array}$} & \multicolumn{2}{|c|}{$\begin{array}{l}\text { Tax subsidy } \\
\text { ratio for large } \\
\text { firms }\end{array}$} \\
\hline & $\mathrm{P}$ & rho-S & $\mathrm{P}$ & rho-S & $\mathrm{P}$ & rho-S & $\mathrm{P}$ & rho-S & $\mathrm{P}$ & rho-S \\
\hline $\mathrm{T}$ & 0,33 & 0,38 & 0,41 & 0,31 & 0,33 & 0,33 & 0,11 & 0,25 & 0,25 & 0,34 \\
\hline $\mathrm{T}-1$ & $-0,8$ & $-0,12$ & $-0,01$ & 0,20 & 0,24 & 0,43 & 0,16 & 0,07 & 0,28 & 0,16 \\
\hline $\mathrm{T}-2$ & 0,19 & 0,34 & 0,11 & 0,10 & 0,13 & 0,13 & 0,36 & 0,38 & 0,34 & 0,19 \\
\hline T-3 & $-0,32$ & $-0,34$ & 0,15 & 0,14 & 0 & 0,16 & \multirow{3}{*}{\multicolumn{4}{|c|}{ Lack of data }} \\
\hline $\mathrm{T}-4$ & $-0,27$ & $-0,21$ & 0,14 & 0,31 & 0,18 & 0,33 & & & & \\
\hline $\begin{array}{c}5 \text { year } \\
\text { aver- } \\
\text { age } \\
\end{array}$ & 0,24 & 0,40 & 0,23 & 0,16 & 0,29 & 0,33 & & & & \\
\hline
\end{tabular}

Source: author's calculations.

A visible polarization of the coefficients' values in the model was observed. The indicators of tax subsidy ratio for SMEs and large firms were bound with the first component with high values of coefficients and with the second component with low values of coefficients. And inversely, the indicators describing the dynamics of the expenditures on research (GOVB, GOVGH and HERD expenditures) were bound with the second component with high values of coefficients and with the first component with low values of coefficients. This result allowed to interpret the obtained model by dividing the observed policy measures into indirect funding (first extracted dimension) and direct funding (second extracted dimension) components.

The distribution of science and innovation policies pursued by the analyzed countries in the new layout is presented on Figure 1. The countries on the right side of the diagram are characterized by a high level of application of tax incentives within their science and innovation policy (ex. France, Spain), whereas the countries on the left side have lack of or apply a very low level of such indirect instruments (ex. Luxembourg, Russia, Slovakia, Poland). In a similar way, the countries on the top of the diagram have experienced growth of direct R\&D funding (ex. Turkey, Russia, Luxem- 
bourg) and the countries in the lower part of the diagram share a slower growth or a decrease of direct funding (ex. Japan, United Kingdom, the Netherlands). The countries for which a moderate dynamics of direct funding as well as moderate level of indirect funding instruments was observed were located in the middle of the diagram.

Figure 1. Distribution of funding instruments of science and innovation policy pursued by the analyzed countries in a two dimensional space

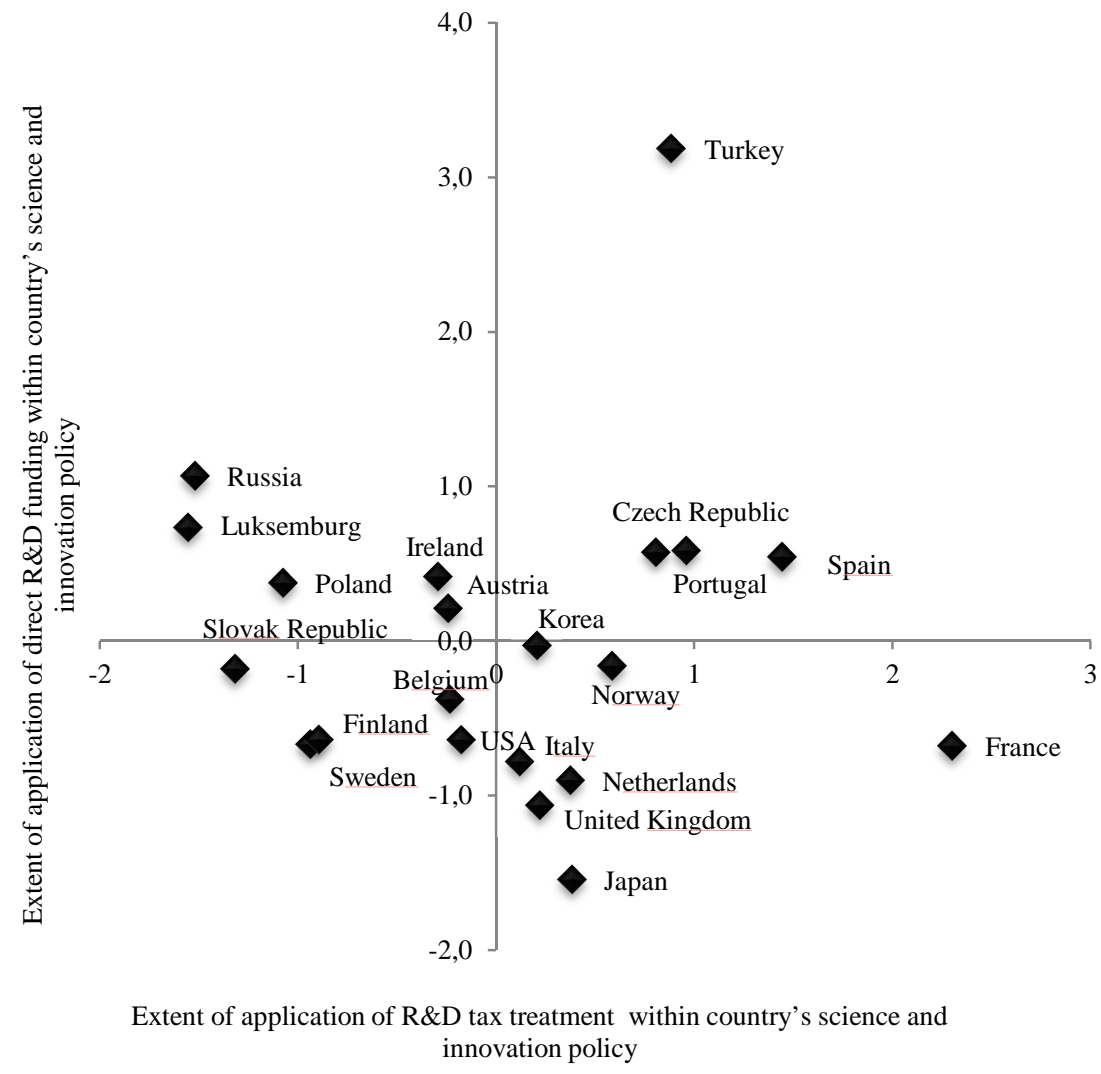

Source: author's calculations. 
Basic relations between extracted dimensions and the level and dynamics of BERD expenditures were discovered basing on measures of causality. Not all statistically significant dependencies discovered in the data have an economic interpretation, but the obtained results are in accordance with basic expectations (see Table 2).

Table 2. Measures of causality between analyzed variables and two extracted principal components

\begin{tabular}{|l|c|c|c|c|c|c|}
\hline Variable & \multicolumn{2}{|c|}{ First component } & \multicolumn{2}{c|}{ Second component } & \multicolumn{2}{c|}{ BERD dynamics } \\
\hline Correlation coefficient & Pearson & Spearman & Pearson & Spearman & Pearson & Spearman \\
\hline BERD dynamics & 0,05 & 0,05 & 0,34 & 0,41 & 1 & 1 \\
\hline BERD intensity in GDP & $-0,05$ & 0,02 & $-0,5$ & $-0,46$ & $-0,38$ & $-0,57$ \\
\hline HERD intensity in GDP & 0,32 & 0,58 & 0,01 & $-0,13$ & 0,04 & $-0,08$ \\
\hline GOVGH intensity in GDP & $-0,13$ & $-0,04$ & 0,06 & $-0,04$ & $-0,23$ & $-0,33$ \\
\hline GOVB intensity in GDP & 0,29 & 0,27 & $-0,54$ & $-0,47$ & $-0,34$ & $-0,37$ \\
\hline
\end{tabular}

Source: author's calculations.

In the analyzed data the influence of direct $R \& D$ funding on business sector activity was proved to be of moderate strength. The dynamics of direct investment, however, appear to be lower in the countries with higher business sector innovativeness, as a significant negative correlation was discovered between these variables. This result may be a consequence of a less classical approach towards policy instruments in countries with higher BERD intensity (see Figure 2). These countries reach for more advanced and complex funding instruments that are better suited for their business sector needs and goals. Such support for business sector R\&D activity is more often applied by means of instruments that among others strengthen intellectual property rights or are based on venture capital. This result may also suggest the existence of a catching-up process of the less innovative economies. Moreover, the measures of causality have showed that this relation is stronger than the influence of pursued R\&D funding policy on BERD dynamics. 
Figure 2. Relation between direct funding component and BERD intensity in GDP

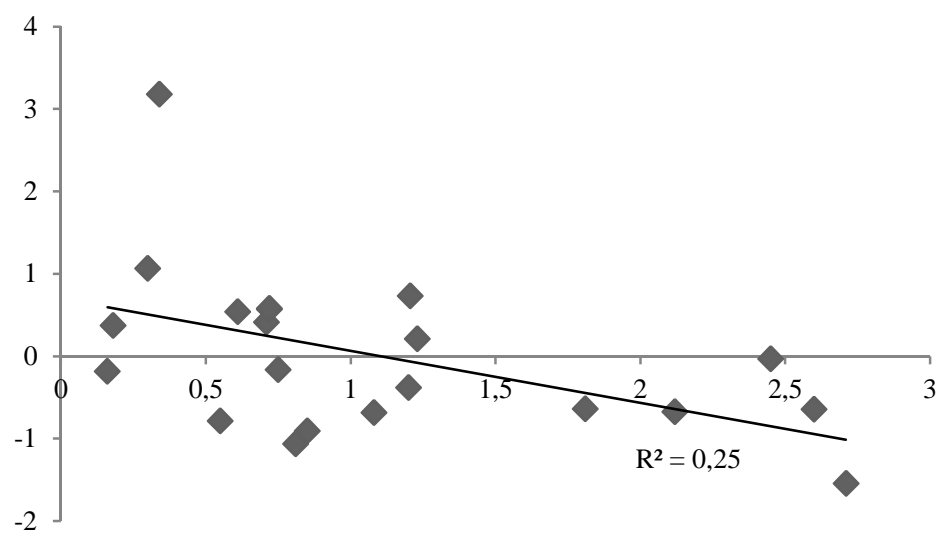

Source: author's calculations.

An interesting result was observed for the indirect funding component and the variables measuring the level of business sector innovativeness. The values of Pearson's and Spearman's correlation coefficients confirm no linear nor monotonous dependency. However, the relation between indirect funding component and the level of BERD intensity in GDP (logarithmized) was represented by an inverted U-shaped curve. In the obtained result, low values of the component were observed for both the countries with very low and the countries with very high business sector innovativeness. Moreover, the countries with a moderate innovativeness level of their business sector were characterized by a high values of the indirect funding component. This result suggests that for the analyzed data the effectiveness of indirect funding instruments was dependent on the level of a country's business sector innovativeness.

Golberg at al. (2011) state that less innovative countries rarely apply indirect funding within their science and innovation policy ${ }^{7}$. A construction of effective policy instruments requires a good understanding of business

${ }^{7}$ The World Bank (Golberg at al., 2011) state four reasons for low effectiveness of tax incentives in less innovative countries. First, indirect funding is not an attractive instrument for start-ups that have yet not accumulated any capital. Moreover, in countries where the collection of taxes is not always effective, providing indirect funding instruments may cause tax evasion. The total management cost of tax incentives is hard to estimate and therefore can exceed initial expectations. Finally, tax incentives are not an effective instrument for building R\&D networks, which should be one of the priorities of science and innovation policy in less innovative countries. 
sector R\&D needs, as well as a mature institutional base to manage such instruments. For this reason, in countries that are in the process of entering the KBE model that share a less adolescent culture of public institutions, effective management of indirect funding instruments is difficult.

More innovative countries often apply indirect funding within their science and innovation policies, which can explain the obtained result of high values of first extracted component for countries with moderate level of BERD intensity in GDP (see Figure 3). Moreover, a growth in the popularity of these instruments has been noted in OECD countries in the last years (OECD, 2011). However, in 2009 the countries like Mexico and New Zealand decided to withdraw tax incentives from their science and innovation policy ${ }^{8}$. This decision was caused by high costs introduction of such instruments. Diversified policy instruments in innovative countries are therefore a result of adjustment of regulations to economic conditions of these countries.

Figure 3. Relation between indirect funding component and BERD intensity in GDP

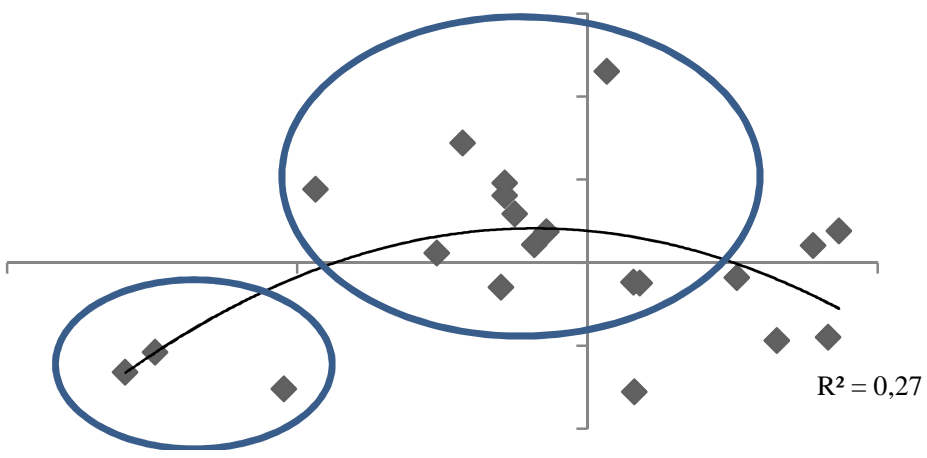

Source: author's calculations.

The mentioned cost can be also a cause of lower interest in indirect funding instruments of most innovative countries. A small profitability in relation to already high innovativeness confronted with the expected cost of introducing tax incentives by a country may stand as an counterargument.

\footnotetext{
${ }^{8}$ The cost of introducing tax incentives can be very high or may be difficult to estimate The estimated cost of introducing tax incentives in New Zealand was at the level of $0,06 \%$ GDP, such estimations for Mexico are unknown.
} 
In the analyzed data, Finland and Sweden were the two countries considered to be of high innovativeness (in 2008: BERD =2,6\% GDP in Finland and 2,1\% GDP in Sweden; source: Eurostat) that did not apply indirect funding ${ }^{9}$. This fact could be explained not only by the mentioned costbenefit arguments but also by already favorable conditions for business activity in these countries and different direction of their science and innovation policy aimed at supporting high level of human capital and a highly qualified work force in their business processes.

The observed strong monotonous relation between the first component and the intensity of HERD expenditures in GDP does not have an economic interpretation.

In the second step of the study, structured data analysis was applied to the extracted components of direct and indirect funding and the measures of BERD dynamics and its intensity in GDP for the analyzed group of countries. The procedure of hierarchical clustering was conducted using two grouping methods. The aim of such clustering was to highlight the basic types of relations between the policy pursued and the activity of business sector by dividing the set of countries into groups of common profiles.

The hierarchical clustering procedure with single linkage method allowed to obtain a ranking of similarities of the profiles of analyzed countries. The result in the form of a dendrogram plot is presented on Figure 4. The obtained result implies that the most similar profile of the analyzed measures was shared by the Czech Republic and Portugal (characterized by a high level of direct and indirect funding, a moderate level of BERD intensity in GDP and an increase of these expenditures), as well as the Netherlands and the United Kingdom (characterized by a high level of indirect funding and a decrease of direct funding, as well as a decrease of BERD expenditures).

\footnotetext{
${ }^{9}$ Fiscal incentives introduction has been a topic of public debate in many countries. As a result, many countries (ex. Germany, Switzerland) have decided to introduce this instrument. In 2012 both Finland and Sweden have introduced tax-incentives to their science and innovation policy.
} 
Figure 4. Plot of dendrogram with single linkage method

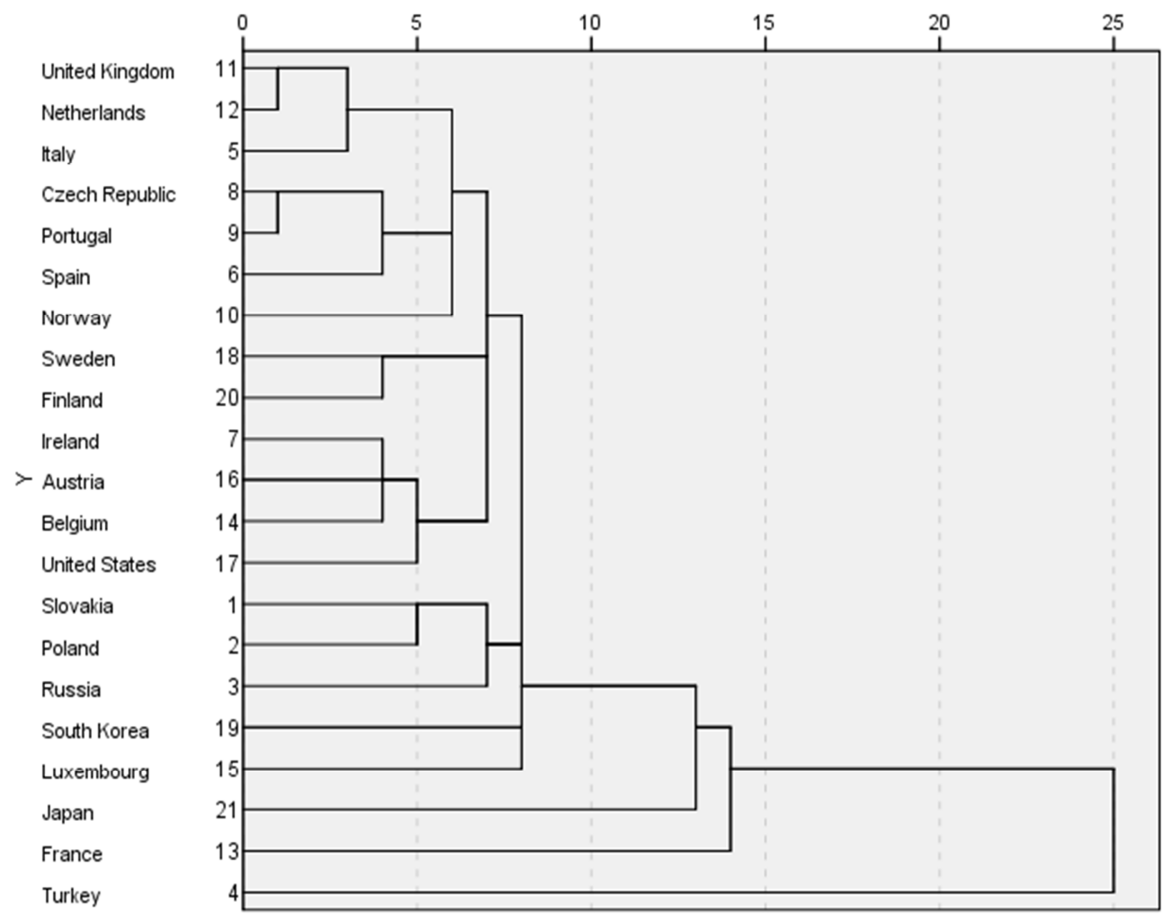

Source: author's calculations.

On the other hand, application of hierarchical clustering procedure using Ward's method resulted in determination of groups of similarities according country's business sector innovativeness profile and its policy-mix. The result in the form of a dendrogram plot is presented on Figure 5. 
Figure 5. Plot of dendrogram with Ward's method

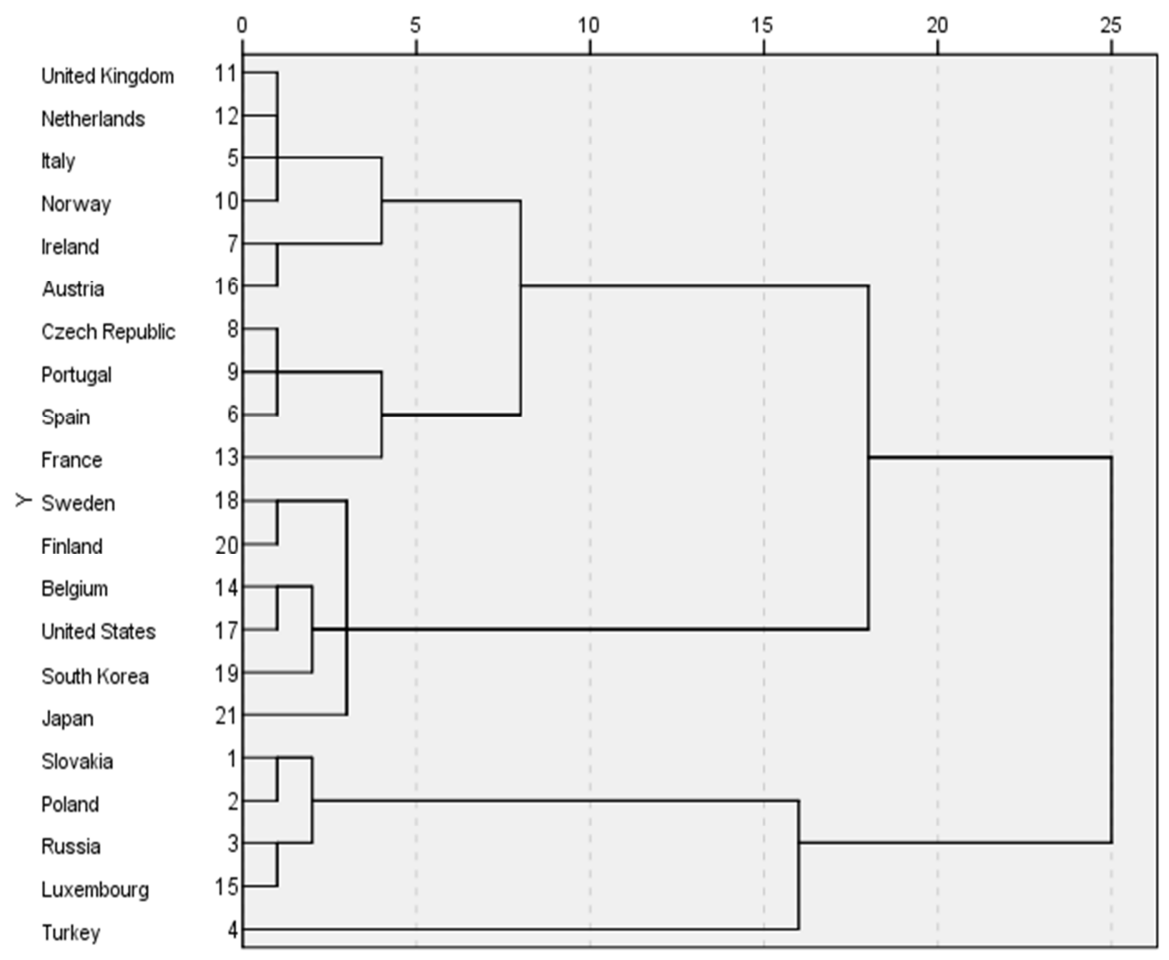

Source: author's calculations.

The procedure disclosed an existence of five groups of countries which were distinct in respect of the analyzed features.

The first group included countries with a simultaneous growth of direct funding and a very high level of indirect funding (the level of indirect subsidies varied between $27 \%$ and $43 \%$ ). This group classified the countries for which a growth of business sector R\&D expenditures was high, independently on the level of BERD intensity in GDP. This cluster included the following countries: Portugal, Spain, the Czech Republic and France.

The second group gathered countries that did not apply R\&D tax incentives or applied them on a very small scale, but have experienced growth of direct funding on R\&D. The growth of direct funding was not observed, however, in all three expenditure flows (i.e. GOVB, GOVGH, HERD) analyzed within the second extracted component. This cluster included Poland, Slovakia and Russia, which were countries with a very low BERD intensity in GDP, but have experienced a growth of these outlays. Also Luxembourg 
was classified within this group with much higher BERD intensity $(1,3 \%$ GDP), but with almost no dynamics (a low decrease) of business sector R\&D expenditures.

The third group classified mostly highly innovative countries (with high BERD intensity in GDP: Japan 2,7\%, Finland 2,6\%, South Korea 2,45\%, Sweden 2,12\%, United States 1,81\% and Belgium 1,21\%) which experienced a mixed dynamics of BERD expenditures. This group classified countries that shared a slow increase of direct funding to R\&D with (except for Japan that experienced a decrease in all analyzed expenditure flows). The countries in the cluster shared a varied policy on $R \& D$ tax incentives. Finland and Sweden did not apply tax incentives within their policies, whereas the rest of the countries classified in this group applied indirect funding instruments (with Japan and South Korea sharing the level of tax subsidy ratio of about $16 \%$ ).

The forth group gathered countries with a moderate level of business sector innovativeness that all applied tax incentives in their science and innovation policy (for some the level of tax subsidy ratio was high and ranged around 20\%: the Netherlands, the United Kingdom and Norway). The countries classified into this group have experienced a decrease or a very small increase of direct funding to $R \& D$. The diversified policy-mix in the analyzed cluster resulted in varied dynamics of BERD expenditures (with growth noted for Italy, Ireland, Norway and Austria and a decrease for the United Kingdom and the Netherlands).

The fifth group consisted of only one country (Turkey), which pursued a very intensive policy of direct $R \& D$ funding (the highest growth of GOVB and HERD expenditures in the analyzed group of countries). In this case, tax incentives were also very favorable (tax subsidy ratio at the level of $22 \%$ for both SMEs and large firms). Although Turkey had low BERD expenditures intensity in GDP $(0,34 \%$ GDP), the growth of these outlays was very high in the analyzed period of time.

To conclude, three of the groups obtained in hierarchical clustering procedure were characterized by a growing dynamics of BERD expenditures supported by either a growing direct funding or a high level of indirect funding (or both). This relation was detected for the first group, the second group (except for Luxembourg), and the fifth group (Turkey). The third and the fourth group classified the countries with very diversified policies and diversified results of BERD dynamics. Most of them had already achieved a high level of business sector innovativeness reflected in the intensity of BERD expenditures in GDP. The results for these groups did not allow to make unambiguous conclusion on the policy influence on BERD dynamics. For the other groups, the expected impact of the policy pursued was noted. 
Moreover, the analysis of obtained results, showed that higher effectiveness of R\&D funding policy was observed for the countries with more polar levels of BERD intensity in GDP (see Figure 6).

Figure 6. Clusters of countries according to science and innovation policy pursued and the dynamics and level of BERD expenditures

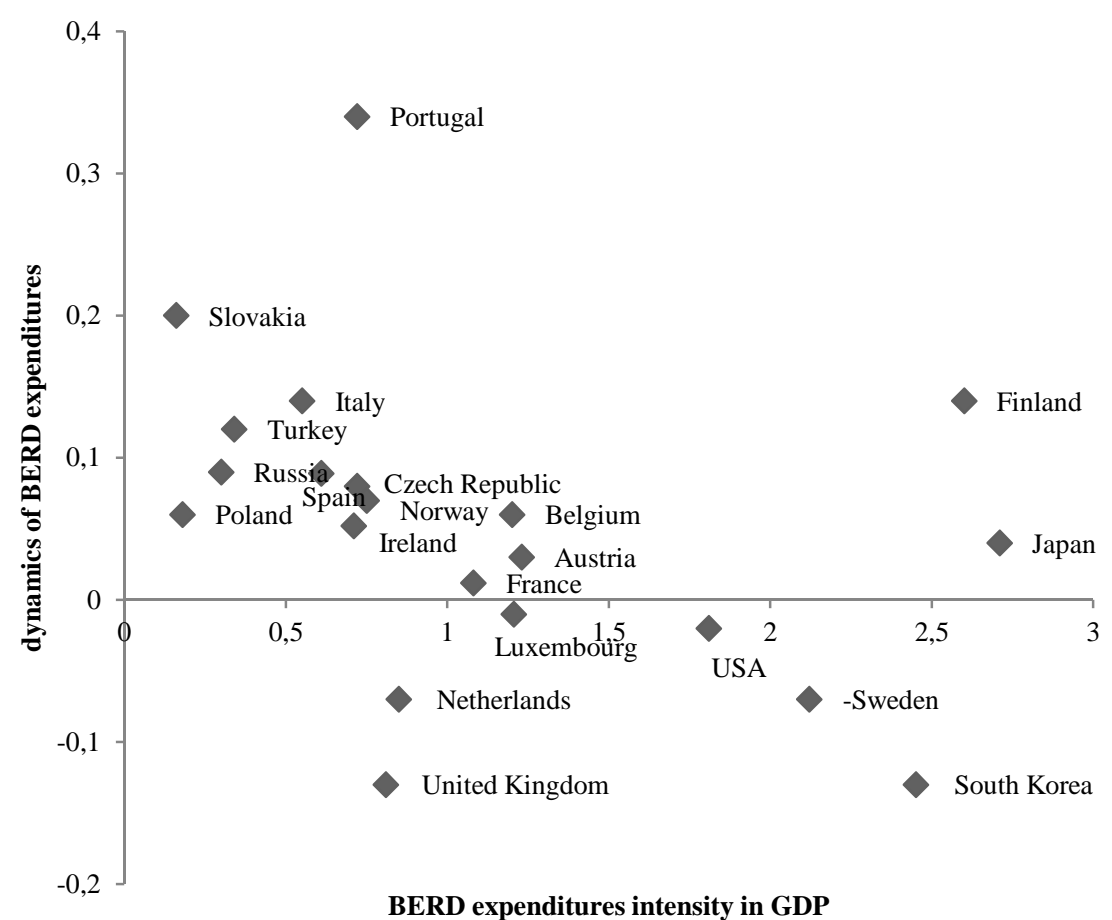

Source: author's calculations.

\section{Conclusions}

The analysis conducted for the selected group of countries for the time period of 2003-2008 showed that direct funding has had a moderate influence on business sector R\&D expenditures dynamics and was found to be decreasing with growing intensity of these outlays. The generosity of country's fiscal incentives on R\&D was proved to be dependent on the level of 
innovativeness of business sector and was represented by an inverse Ushaped curve.

Moreover, the analysis has showed that the influence of the level of business sector innovativeness on business sector R\&D funding was stronger than the influence of the pursued R\&D funding policy. This result may be a reflection of more innovative countries' tendency to adopt different, more advanced R\&D support instruments.

The hierarchical clustering procedure allowed to build a ranking of countries based on the similarity in R\&D funding profile and its effectiveness. Moreover, it allowed to determine groups of countries with visible influence of their pursued policy on business sector R\&D activity. This analysis showed that the influence of pursued policy on business sector R\&D outlays dynamics was more visible for countries with more polar level of business sector innovativeness. The countries with lower intensity of BERD expenditures in GDP generally demonstrated a higher dynamics of direct funding on $\mathrm{R} \& \mathrm{D}$, but have rarely applied indirect funding instruments. Tax incentives have been generally more effective in the countries with higher business sector innovativeness, but in the case of innovation leaders have not always been an optimal instrument to support innovativeness.

The conducted analysis allowed to state that the effectiveness of science and innovation policy instruments is determined by the level of country business sector innovativeness (BERD intensity in GDP). This level should be a key factor in determining R\&D funding strategies, as these economic considerations influence the dynamic of innovation process and the functions of pursued science and innovation policy. Direct funding policies are more effective in countries situated below the technology frontier. These countries more often uptake imitation activities which allow them to profit from knowledge spillover. An effective use of indirect R\&D funding instruments is, however, possible in countries with at least a moderate level of business sector innovativeness.

Diversified levels of analyzed indicators reflecting varied policy strategies of R\&D funding and varied innovation levels in the observed group of countries hamper building unambiguous conclusions. In order to define most effective science and innovation policies, the influence of public support on the process of innovation should be observed in a long term. Analyzing other than financial instruments of science and innovation policy could be an interesting extension of the presented analysis. 
Appendix 1. The matrix of coefficients after varimax rotation, describing the binding of the analyzed measures with the constructed components

\begin{tabular}{|l|c|c|}
\hline \multicolumn{1}{|c|}{ Indicator } & First component & Second component \\
\hline GOVB expenditures & 0,186 & 0,925 \\
\hline HERD expenditures & 0,193 & 0,678 \\
\hline GOVGH expenditures & $-0,369$ & 0,568 \\
\hline Tax subsidy for SMEs & 0,971 & 0,045 \\
\hline Tax subsidy ratio for large firms & 0,948 & 0,165 \\
\hline
\end{tabular}

Source: author's calculations.

\section{References}

Arrow K. J. (1962), Economic Welfare and the Allocation of Resources to Invention [in:] R.R. Nelson (ed.), The Rate and Direction of Economic Activity, Princeton University Press, New York.

Bloom N., Griffith R. (2001), The Internationalization of UK R\&D, "Fiscal Studies", Vol. 22, No. 3.

European Commission (2010), Europe 2020 - A European strategy for smart, sustainable and inclusive growth. Communication from the Commission, European Commission, Brussels.

Falk M. (2004), What Drives Business $R \& D$ across OECD Countries?, Working paper, Austrian Institute of Economic Research, Vienna.

Goldberg I., Goddard J.G., Kuriakose S., Racine J.L. (2011), Igniting Innovation: Rethinking the Role of Government in Emerging Europe and Central Asia, The World Bank, Washington DC.

Griliches Z. (1979), Sibling Models and Data in Economics: Beginnings of a Survey, "Journal of Political Economy", Vol. 87, No.5, http://dx.doi.org/10.1086 1260822.

Guellec D., van Pottelsberghe de la Potterie B. (2003), The Impact of Public R\&D Expenditure on Business $R \& D$, "Economics of Innovation and New Technology”, Vol. 12, No. 3, http://dx.doi.org/10.1787/670385851815.

Howitt P. (2000), Endogenous Growth and Cross-Country Income Differences, "American Economic Review", Vol. 90, No. 4, http://dx.doi.org/10.1257/aer. 90.4.829.

Jones B. F. (2011), As science evolves, how can science policy?, National Bureau of Economic Research.

Jones C., Williams J. (1998), Measuring the Social return to $R \& D$, "Quarterly Journal of Economics", Vol. 113, No. 4, http://dx.doi.org/10.1162/003355 398555856.

OECD (2011), The international experience with $R \& D$ tax incentives, http://www.finance.senate.gov/imo/media/doc/OECD $\% 20 \mathrm{SFC} \% 20 \mathrm{Hearing} \% 20$ testimony\%209\%2020\%2011.pdf 
Moen J. (2007), Should Finland introduce an R\&D tax credit? Reflections based on experience with Norwegian $R \& D$ policy, The Research Institute of the Finnish Economy, Discussion paper no. 1097, Helsinki.

Policy instruments for sustainable innovation (2004), Technopolis, Amsterdam.

Romer P. (1990), Endogenous Technological Change, "Journal of Political Economy", Vol. 98, No. 5, http://dx.doi.org/10.1086/261725.

Saplolsky H. M, Taylor M. Z. (2011), Politics and the Science of Science Policy [in:] Fealing K.H., Lane J.I., Marburger III J.H., Shipp S.S. (ed.), The Science of Science Policy, Stanford Business Books, Stanford.

Stewart L.A., Warda J., Atkinson R. D. (2012), We're \#27!: The United States Lags Far Behind in R\&D Tax Incentive Generosity, The Information Technology and Innovation Foundation.

Tewksbury J.G., Crandall M.S., Crane W.E. (1980), Measuring the Societal Benefits of Innovation, "Science", Vol. 209, No. 4457, http://dx.doi.org/10.1126/ science.209.4457.658.

Warda, J. (2001), Measuring the Value of $R \& D$ Tax Treatment in OECD Countries, "STI Review", Vol. 27, Special Issue on New Science and Technology Indicators. 